\title{
SESSION VII APPLICATIONS OF MICROCOMPUTERS IN TEACHING
}

\author{
N. John Castellan, Jr., Presider
}

\section{Selection of software in the instructional laboratory}

\author{
DARRELL L. BUTLER \\ Ball State University, Muncie, Indiana
}

\begin{abstract}
In this paper, I discuss a number of issues concerning software selection in instructional laboratories. First, I describe several taxonomies of instructional software and argue that the most important dimension of instructional software is that it must be an efficient tool. Second, I discuss some elements of the context of the instructional lab, including sophistication of users. Third, I explore design features, especially those related to ease of learning to use packages. Several other issues are also considered, such as where to find software reviews.
\end{abstract}

Computerized instructional laboratories are becoming more common in psychology (Bharucha, Meike, \& Baird, 1987; Goolkasian, 1985). The purpose of this paper is to describe a number of important considerations in selecting software for instructional laboratories. These considerations have been gleaned from recent papers and from my own experiences. They are divided into four categories: taxonomy of the software, context of software use, design features, and other considerations.

\section{Taxonomy of Software}

Several taxonomies of instructional software have been described. Castellan (1983) discriminated among drill and practice software, data generators, experiment simulators, and games. Taylor (1980) distinguished among software as tutors, tools, or tutees. Collyer (1984) proposed that software fosters thinking when students program, replace things that work, simulate, provide behavior, and pose problems. Hewett (1986) integrated previous taxonomies into a three-dimensional model that he refers to as a courseware taxonomy: types (practice, data generators, experiment simulators, and micro-world simulators), sources (real and imaginary), and goals (pose, provide, create, simulate, develop, and replace).

Although helpful in some circumstances, the careful categorization of software may be misleading. Consider the following examples. One good software tool is a word processor, which can be used to accomplish many different tasks. Obviously, students can use word processors

Address correspondence to Darrell L. Butler, Department of Psychology, Ball State University, Muncie, IN 47306. to type papers, but word processors can also be used instructionally to study a variety of human factors issues involving human-computer interfaces. Spreadsheets can be used to keep class records, but Hewett (1985) has shown that a spreadsheet program can also be used to model neural networks. Because word processors and spreadsheets are such general-use tools, it is difficult to categorize them accurately using Hewett's model or the others that have been proposed.

Rather than carefully categorizing software, as implied by Hewett (1985), I believe it is wiser to question whether particular software can be a good tool for working on one or more tasks. In other words, software must be a useful tool. A recent survey of academic psychologists by Carpenter (1986) is interesting in this light. Carpenter found that microcomputers were most valued for their word processing ability, which is useful in research, teaching, and administrative tasks. The other highly valued software packages are programming languages, databases, and spreadsheets. All of these types of software are useful tools. Castellan (1987) argued that many tools will have even greater use in the future: text processors, database inquiry systems, and problem solving tools.

Some of the tools (other than programming languages) that can be of value to students working in an instructional laboratory are word processors, statistics calculators, programs that create graphic displays of data, programs aiding electronic mail, packages that run computer experiments, programs that provide information, and programs that allow information in databases to be manipulated (e.g., to sign up to participate in experiments). There are some additional tools that can be of value to instruc- 
tors (and perhaps also to students): authoring languages, spreadsheets, and test generators.

Over the past few years, I have found it easy to encourage students to use computers as tools. Students who have used word processors seriously contemplate buying a computer. Students who have used computers to calculate Pearson $r s$ and analyses of variance have trouble imagining why someone would want to do these calculations with a hand calculator. Students who have used computers to run experiments appreciate computers that serve as research assistants.

Tools vary in the flexibility with which they can be used. Consider some of the varieties of packages that allow a computer to act as a research assistant. One type, data generators, allow students to select and manipulate variables that are then used to generate artificial data. This type is limited to artificial data domains and, as far as I can tell, are not very popular today. Another type, experiment simulators, permit students to run themselves and others as subjects in programmed experiments. The computer presents instructions and stimuli, collects responses, and stores responses so they can be analyzed later. This type of package is more flexible and is used more in psychology than are data generators. The third type, experiment generators, are similar to experiment simulators except they give students the ability to change experimental conditions and create new stimuli. These are very flexible tools. Several recent papers discuss new experiment generators (Butler, 1988; Constin, 1988; Foltz \& Poltrock, 1988; Schneider, 1988).

Statistics packages and many of the other tools listed above also vary greatly in flexibility. It is not yet clear whether the best tools are the most flexible ones. Carpenter's (1986) survey on software is clearly biased toward general-use tools because it primarily summarizes frequencies across the sample. Very useful tools to a small group of psychologists would not appear very important in Carpenter's survey. Although I have no data, I suspect that many of the best tools are very general purpose, although a good software library should probably contain some less flexible software that is particularly useful for one or a few tasks.

\section{Context of Software Use}

Users of instructional software vary widely in their computer sophistication. This, in turn, has effects on many decisions regarding software. For example, should the software be extremely easy to learn to use? If users are relatively sophisticated or will probably be using the software over substantial time, then ease of learning may not be a priority. However, fast-rising learning curves have many advantages. Unsophisticated students may attribute slow progress to themselves (rather than the software) and give up using it. More will be said about factors affecting ease of learning later in this paper.

A second concern is relating the software to specific classes. In order to accommodate a variety of textbooks, teaching styles, and interests, we have found it advanta- geous to have several different tools that can be used for any particular task. This can create compatibility problems of various kinds. Some incompatibility must be tolerated, but there are also some hardware and software tools that help alleviate these problems. For example, some statistics packages and some special-use software can read and write files in a wide variety of data structures.

Hardware constrains software. The Apple II still appears to be the most common instructional computer, but software for IBM PCs (and compatibles), Macintoshes, and Commodore $64 \mathrm{~s}$ is available. There are advocates of each machine. Among the arguments for various machines are the following: There is more software available for the Apple II series computer than any other. The IBM PC has greater capacity and speed than older Apple II microcomputers. Excellent learning curves are obtained with the Macintosh. Commodore computers are very inexpensive. For all of these machines, one can obtain printers, modems, and other peripherals. The choices of software and the flexibility with which they can be used depend upon the types and varieties of peripherals available. If you have obtained (or are planning to obtain) a variety of peripherals, then plan to obtain software tools that have the flexibility and power to use the peripherals.

\section{Design Features}

There are several design characteristics that should be attended to: ease with which the package can be learned, accuracy, compatibility of data structures, and modifiability.

A number of variables are related to easy-to-learn and easy-to-use programs. These have been discussed in various papers (Butler, 1986b; Butler \& Eamon, 1985). In general, for making choices and moving through large programs, menus are easier to learn to use than are command languages. Consistent interactions with the computer aid learning. This may be one reason why programs using the mouse are easy to learn to use. Screens should contain adequate information, but should not be overwhelming. Easy-to-learn programs often provide a way to escape or return to some earlier point in the interaction. Easy-to-learn software typically handles errors by providing appropriate messages and suggesting appropriate behavior to the user. Help messages (or an onscreen manual) can save time, reduce errors, and increase the speed of learning (Cohill \& Williges, 1985).

Software should be accurate. Information presented should be correct. Calculations, such as statistics, should be correctly computed. It is surprising how often statistics packages have major problems producing the correct statistics (Butler \& Eamon, 1985; Butler \& Jones, 1987).

When many different packages are being used, compatibility of stored data can become an issue. It is inefficient for computerized experiments to save data in a form that cannot be used by any statistics package. It is frustrating if the package that plots data graphs cannot use the same files as the statistics package. Sometimes packages are sold as source code. If experts are around, they 
may be able to alter the programs to be more compatible. More likely, they may be able to write programs that translate one data structure into another.

Similar problems arise with the software itself. Can it be copied? Is it transferable to a hard disk? These problems are not always addressed by software vendors. Copyable programs are highly desirable for instructional laboratories.

\section{Other Considerations}

Price of software should be reasonable. Some expensive software is not worth the price. You can often make a good decision about the value of software if you search for good reviews, especially ones that compare packages. Recent reviews on statistics have been published (Butler \& Eamon, 1985; Butler \& Jones, 1987; Lehman, 1986), and new ones regularly appear in various journals (e.g., American Statistician and Behavior Research Methods, Instruments, \& Computers). Some recent papers have reviewed data generators, experiment simulators, and experiment generators (Butler, 1988; Eamon \& Butler, 1985). Contemporary Psychology has begun to carry software reviews (Butler, 1986a). One journal, Social Science Microcomputer Review, is dedicated to reviews. Also various popular magazines (such as BYTE and $A+$ ) carry review articles that are very useful. Hopefully, all of these journals and magazines will continue to review software that will point to the value of software tools for psychologists.

\section{REFERENCES}

Bharucha, J. J., Meike, B., \& Baird, J. C. (1987). The Macintosh as a user-friendly laboratory for perception and cognition. Behavior Research Methods, Instruments, \& Computers, 19, 131-134.

BUTLER, D. L. (1986a). Elementary statistics packages for microcomputers. Contemporary Psychology, 31, 485-487.

BUTLER, D. L. (1986b). Integrating statistical software into laboratories and laboratory courses. Behavior Research Methods, Instruments, \& Computers, 18, 241-244.
BUTLER, D. L. (1988). A critical evaluation of software for experiment development in research and teaching. Behavior Research Methods, Instruments, \& Computers, 20, 218-220.

Butler, D. L., Eamon, D. B. (1985). An evaluation of statistical software for research and instruction. Behavior Research Methods, Instruments, \& Computers, 17, 352-358.

BUTLER, D. L., JoNes, S. K. (1987). A comparison of inexpensive statistical packages for Apple II microcomputers. Behavior Research Methods, Instruments, \& Computers, 19, 99-103.

Carpenter, D. L. (1986). A survey of microcomputer use in small psychology departments. Behavior Research Methods, Instruments, \& Computers, 18, 155-156.

Castellan, N. J., JR. (1983). Strategies for instructional computing. Behavior Research Methods \& Instrumentation, 15, 270-279.

Castellan, N. J., JR. (1987). Computers and the shape of the future: Implications for teaching and learning. Education \& Computing, 3, 39-48.

Cohill, A. M., \& Williges, R. C. (1985). Retrieval of HELP information for novice users of interactive computer systems. Human Factors, 27, 335-343.

COLlyer, C. E. (1984). Using computers in the teaching of psychology: Five things that seem to work. Teaching of Psychology, 11, 206-209.

Costin, D. (1988). MacLab: A Macintosh system for psychology labs. Behavior Research Methods, Instruments, \& Computers, 20, 197-200.

EAMON, D. B., \& BUTLER, D. L. (1985). Instructional programs for psychology: A review and analysis. Behavior Research Methods, Instruments, \& Computers, 17, 345-351.

GoOlKasian, P. (1985). A microcomputer-based lab for psychology instruction. Teaching of Psychology, 12, 223-225.

HEWETT, T. T. (1985). Teaching students to model neural circuits and neural networks using an electronic spreadsheet simulator. Behavior Research Methods, Instruments, \& Computers, 17, 339-344.

HewETt, T. T. (1986). When every student has a computer: A new perspective on courseware and its development. Behavior Research Methods, Instruments, \& Computers, 18, 188-195.

Lehman, R. S. (1986). Macintosh statistical packages. Behavior Research Methods, Instruments, \& Computers, 18, 177-187.

Poltrock, S. E., \& Foltz, G. S. (1988). APT PC and APT II: Experimental development systems for the IBM PC and Apple II. Behavior Research Methods, Instruments, \& Computers, 20, 201-205.

SCHNEIDER, W. (1988). Micro Experimental Laboratory: An integrated system for IBM PC compatibles. Behavior Research Methods, Instruments, \& Computers, 20, 206-217.

TAYLOR, R. P. (1980). The computer in the school: Tutor, tool, and tutee. New York: Teachers' College Press, Columbia University. 